American Journal of Economics and Business Administration 3 (1): 197-202, 2011

ISSN 1945-5488

(C) 2010 Science Publications

\title{
Design Strategies to Persuasive Learning for Promoting Sustainable Practices in Paddy Farming
}

\author{
${ }^{1}$ Zakirah Othman and ${ }^{2}$ Amran Muhammad \\ ${ }^{1}$ College of Business, Technology Management Building, \\ University Utara Malaysia, 06010, Sintok, Kedah, Malaysia \\ ${ }^{2}$ Department of Science and Technology Studies, Faculty of Science, \\ University Malaya, 50603 Kuala Lumpur, Malaysia
}

\begin{abstract}
Problem statement: Public awareness of sustainable agriculture is low, especially in organic paddy practices. As alternative, introducing Information and Communication Technology (ICT) application like electronic learning is an effective way to educate and promote the young generation to appreciate sustainable agriculture. Therefore, the main objective of this study is to discuss a design of a prototype of persuasive learning in virtual paddy as a tool to promote sustainable practices in paddy farming using Malaysia paddy farming practices as a case study. Approach: The real practice in sustainable paddy farming practices has been adapted in design of prototype. A method used for prototype design and development in this study is adapted from the model for design and development created by Alessi and Trollip. After that, a pilot test will be conducted with the help of an expert user. In addition, a lab experiment was conducted in the Computer Laboratory of the Engineering Department, University Putra Malaysia. Respondents from the Biology, Engineering and Agriculture Department student, Faculty of Engineering were selected randomly to answer the usability and awareness questionnaire. Results: Finding of this study shown the way of information and communication technology can facilitate understanding in organic paddy farming practice. The prototype also improves the level of awareness in sustainable agriculture in general. Conclusion/Recommendations: For future study, more research about potential used of learning environment in the sustainable issues can be carried out.
\end{abstract}

Key words: Sustainable practices, paddy farming, virtual reality, design strategies

\section{INTRODUCTION}

Knowledge Management (KM) refers to a multidisciplined approach to achieve organizational objectives by making the best use of knowledge. Electronic learning can be an effective medium for disseminating knowledge management and this study discusses a preliminary study in design strategies for promoting sustainability in paddy farming.

Creating awareness in sustainable agriculture: According to the National Green Technology Policy Malaysia, effective promotion and public awareness are two of the main factors that would affect the success of sustainable development through the Green Technology agenda. This is particularly significant as such adoption requires a change of mindset of the public through various approaches including effective education and information dissemination to increase public awareness of sustainable agriculture and on ways to conserve the environment. Mustapha and Jani (1995) also state, awareness among society about environmental pollution and resources extinct can help Malaysia to develop sustainable agriculture. More intensive monitoring and investigating the agricultural practices would enable Malaysia to achieve sustainability (Murad et al., 2008). As a solution, introducing the use of virtual technology through learning as a tool to promote sustainable awareness in paddy farming practices in order to increase public awareness is among the best alternatives available.

Organic rice farming practice in Malaysia: Organic farming is increasingly recognized worldwide, as one of the suitable models for creating environmental, economical and social sustainability in agriculture. Ministry of Agriculture Malaysia define organic farming is a crop production system that avoids the use

Corresponding Author: Zakirah Othman, College of Business, Technology Management Building, University Utara Malaysia, 06010, Sintok, Kedah, Malaysia Tel: 603 -79674275 Fax: 603-79674396 
of synthetic fertilizers and pesticides, hormones, antibiotic and takes measures to protect the environment. Crop diseases and pests are managed by mechanical methods, cultural, biological physical and the use of bio-pesticides. So, organic agriculture practices are committed to balance with nature.

The Department of Agriculture (DOA) is the agency under the Ministry of Agriculture and Agrobased Industry that involves activities in quality and productivity of crop in Malaysia. The department produces Malaysia Organic Scheme to promote sustainable development. Malaysia Organic Scheme is a certification program to recognize farms which cultivate crops organically according to the criteria and requirement spelt out in Malaysia Organic Scheme Standard. The standard is essentially based on the Malaysian Standard, MS 1529: 2001. Kahang Organic Rice farm is the first and only certified organic rice farm in Malaysia since 2005. Another locations fully integrated sustainable paddy field in West Malaysia is Tunjung in Salor area, Kelantan.

ICT application in learning and promote sustainable issues: Sustainability is now becoming both an important concept and a practice for society, economics and the environment (Goodland 1995; Ismail, 2006; Kajikawa et al., 2007). Sustainability in agriculture refers to the farmer's ability to maintain production and give benefits based on maintaining nature and the environment, accelerating the social growth, stabilizing the economy and being a commercially good competitor in the fast changing environment (Ismail, 2006). Further, sustainable agriculture covers both the aspects of production and preserving the environment. It means sustainable agriculture integrates three main goals, environmental health, economic profitability and social and economic equity. These goals have been defined by a variety of philosophies, policies and practices, from the vision or perceptions of the farmers and the consumers.

Learning through virtual reality: Virtual Reality (VR) is a computer technology to create a simulated, three-dimensional world that a user can manipulate and explore while feeling as if he were in that world. The potential of VR technology for supporting education is widely recognized. Many researchers found that virtual reality offers many benefits that can support learning. Some of the benefits include the meaningful learning, easy and better understanding of the learning contents.

There are several successful implementations of elearning such as Pereira (2006), Kuo et al. (2004);
Salam et al. (2010) and Buntod et al. (2010) those discussed in the next sections.

VIRTU@LIS: VIRTU@LIS, funded under the Information Society Technologies (IST) Programme, explored the potential of new digital and multimedia technologies to increase awareness of environmental management and risks in four domains-agricultural pollution, climate change, freshwater and fisheries. The prototype enables visitors to learn about how their lifestyle and behavior affects the environment (Pereira, 2006).

Ecological farmland navigating system: Council Of Agriculture, Taiwan (COA), promoted the importance of farmland conservation to help the elementary education authority on basic agricultural and ecological education. In this study, a 3-D virtual environment is developed to display the virtual farmland theme and associated temporal and spatial data and information (Kuo et al., 2004; 2007).

Garden alive: The Garden Alive aims to provide both entertainment and education. The system has adapted the L-system, so the virtual plants grow in a similar manner to real plants. In this proposed "Garden Alive" system, there are several kinds of plants and each has different genes that are individually unique.

Based on these literatures, learning using ICT applications and ICT have been widely used to improve the agricultural sector.

\section{MATERIALS AND METHODS}

The research involves several stages (Fig. 1 and 2). The first stage understands the problem domain and situation of practices of paddy farming in Malaysia. The real practice in sustainable paddy farming practices will adapt in design of education prototype using multimedia and virtual reality software.

In the first stage, the method involved participatory observation and interviews at four selected locations in West Malaysia, which are Mada, Sabak Bernam, Tunjung and Kahang. The respondents are farmers, researchers and agriculture officers. The results show, there are several similarities and differences in the practice of paddy farming in four selected locations in Malaysia. To summarize, paddy farming practices in Sabak Bernam and MADA can be categorized as the conventional practice while paddy farming practices in other places can be categorized as the sustainable practice (Othman et al., 2010). Finding of this study also shown level of awareness among farmer and society is low.

The second stage is the design and development of a persuasive learning environment. Several design and 


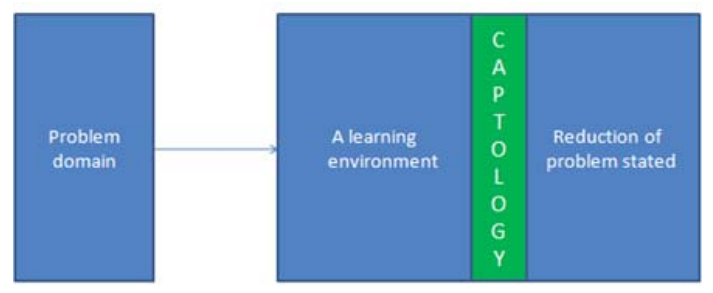

Fig. 1: Generic model of the study

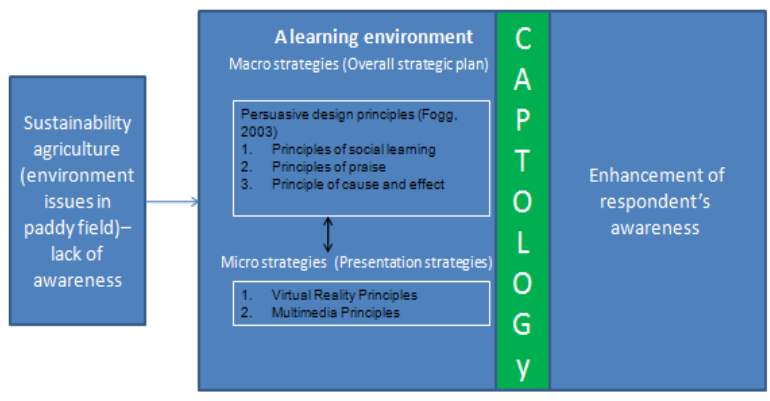

Fig. 2: Specific model of the study

development models were used in the developing of this prototype. Evaluation by experts and consumers was also carried out.

Model for design and development: A methodology used for prototype design and development in this study is adapted from the model for design and development created by Alessi and Trollip (2001). There are three main components in this model which are planning, design and development. Figure 3 illustrates how each component is linked to the others. The Model of Instructional Design by Alessi and Trollip (2001) was chosen as the methodology in this study because this model proposes a set of standards that should guide the design and development study, suggest ways of being creative and introduce techniques for designing, developing and integrating the various components of multimedia application (Alessi and Trollip, 2001).

Planning: There are four steps identified in this phase for planning a design of a persuasive learning environment. The steps are determining the scope of the project, identifying the characteristics of the learner, establishing the constraints and determining and collecting the resources.

Design: In this research, the learning outcome of a persuasive environment is to persuade society to enhance its sustainable awareness in paddy farming practices. In the design phase, the intended outcomes

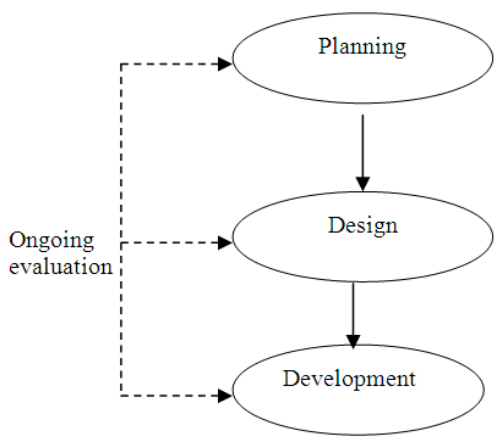

Fig. 3: The model for design and development

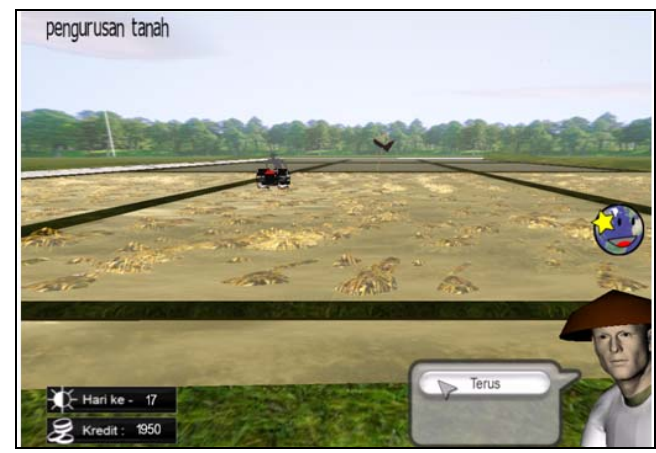

Fig. 4: A snap-shot screen of the simulated paddy farming practices

will link to the requirements and constraints of the prototype. Further, a conceptual model including theories, principles and guidelines are used to engage people in such a way that learning takes place in an effective and efficient manner.

There are four steps identified in this phase for planning a design of a persuasive learning environment. The steps are developing the content ideas, preparing storyboards, preparing scripts and preparing a prototype. In addition, there are four design principles involved in this prototype. They are persuasive design principles, multimedia design principles and virtual reality design principles.

Virtual Reality and multimedia have the advantages of being used as persuasive technology. Fogg (2002) has coined a word 'captology' that is about understanding how what is known about motivation and persuasion can be applied to computers. Captology focuses on attitude and behavior change resulting from human-computer interaction. There are three persuasive principles that have been applied in this study. They are the principle of cause and effect, the principles of praise and the principle of social learning.

Principles of cause and effect: In principles of cause and effect, simulation can persuade people to change 
their attitudes or behaviors by enabling them to observe immediately the link between cause and effects (Fogg, 2002). The example of persuasive cause and effect simulation is a simulation games in paddy farming (Fig. 4). The story of paddy farming practices is based on real data, started in first day. Based on it, if user doing the correct answer to handle paddy farming practices, the character called 'earth' will appear in happy condition and it will support by good sound. In contrast, if user choices the wrong answer, the bad earth character will appear to show the bad impact to environment.

Principle of praise: One of the most powerful persuasive uses of language is to offer praise. By offering praise, via images, words, symbols, or sounds, computing technology can lead users to be more open to persuasion (Fogg, 2002). In this learning prototype, praises are provided through words, sound, symbols and visuals. For example, in the ending of games of simulation paddy farming practices as illustrated in Fig. 5, the user will receive feedback when finish the games like "Tahniah" or 'Congratulation and praise via a star symbol.

Principle of social learning: Social learning theory was developed by psychologist Albert Bandura is broad in scope, but one aspect is relevant to connected technologies is the power of modeling. Research on social learning theory has shown that people learn new attitudes and behaviors by observing others' actions and then noting the consequences of those actions. According Fogg (2002), a person will be more, motivated to perform a target behavior if he or she can use computing technology to view others performing the behavior and being rewarded for it. In this learning

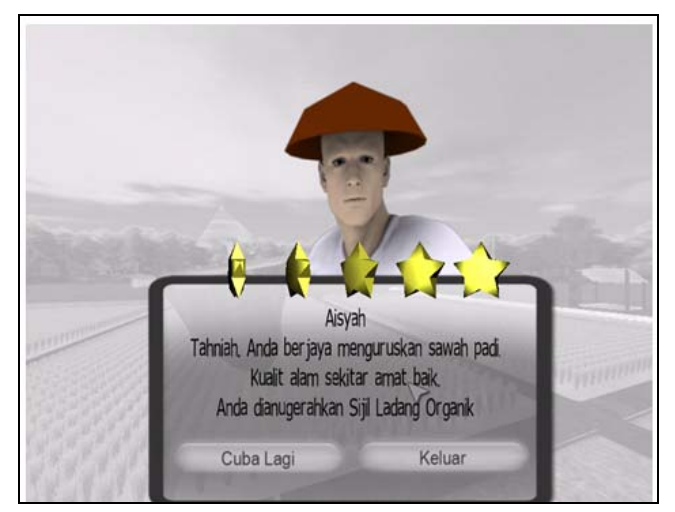

Fig 5: A snap-shot screen of the prototype when user finishes the games environment, the experience at four selected location paddy farming practices was shown in video clip, image and virtual environment. Using this technique, user can view several real practices in paddy farming.

Development: This phase is the implementation of a prototype's design which includes the development process of a non-immersive VR desktop (Kalawsky, 2001) and Alessi and Trollip (2001) model. There are eight steps involved in the development phase which are the production of the text, graphics, audio and video, assembling all the pieces, preparing the support materials, doing an alpha test, doing revision and doing the beta test (Alessi and Trollip, 2001). After that, the prototype was evaluated by an expert.

\section{RESULTS AND DISCUSSION}

In the pilot test, expert reviews are needed to go through the programe to evaluate the content, the flow of the material, the user interface and the usability of the prototype. There are two experts identified for this study which are the subject matter expert and the user interface expert. The subject matter expert's responsibility is to review the accuracy, significance and comprehensiveness of the content. The content is about sustainable paddy practices. An expert reviewer from University Kebangsaan Malaysia was chosen to evaluate the content. Three sessions of interviews and discussions were conducted.

The responsibility of the user interface expert is to examine the interface of the prototype and judge its compliance with recognized usability principles (the heuristics). Two user interface experts from University Utara Malaysia were selected for this phase (ongoing evaluation design process).

In addition, a laboratory experiment was conducted in the Computer Laboratory of the Engineering Department, University Putra Malaysia (UPM) on the $8^{\text {th }}$ of April 2010. 50 respondents from the Biology, Engineering and Agriculture Department student, Faculty of Engineering were selected randomly to answer the usability and awareness (knowledge and understanding) questionnaire. UPM previously was known as the School of Agriculture where the main focus of this school to produce agriculture professional in Malaysia.

In summary, the usability result shows the learning prototype has the potential to be a communication tool, particularly to be used in promoting sustainable issues and enhancing the level of awareness in sustainability. The result shown 94\% respondents agree this system give more understanding in organic paddy farming 
practice. They (96\%) also state the prototype has been successful in creating awareness among respondents. In addition the mean from five scales for overall reaction to the prototype is 4.15 . However, this study does not aim to discuss the detailed results, but it is just to highlight the design strategies of the model.

\section{CONCLUSION}

In brief, knowledge and information have become the medium to generate and disseminate sustainable agricultural knowledge and technology for environmental, social and economic sustainability. Sustainable agriculture has an important role to play in improving the quality of human lives and the environment. In doing so, technology should be used to facilitate sustainable practices in farming activities. From the study, it has been shown that using Information and Communication Technology (ICT) tools in the learning environment can be used to educate and promote sustainable practices to the public. However, other factors such as good perceptions (Bagheri et al., 2008), interactive and cooperation between farmer, government, research institution and policy-maker are important factor in achieving sustainable agriculture (Murad et al., 2008; Sharghi et al., 2010).

For future study, more research on potential used of interaction media and learning environment in the sustainable agriculture issues can be carried out.

\section{ACKNOWLEDGEMENT}

Special thanks to the Ministry of Malaysia Higher Education and Institute of Research Management and Consultancy (PS368-2009C), University of Malaya for the financial support in carrying out this study.

\section{REFERENCES}

Alessi, S.M. and S.R. Trollip, 2001. Multimedia for Learning: Methods and Development. 3rd Edn., Allyn and Bacon, Massachusets, ISBN: 0205276911, pp: 580.

Bagheri, A., H.S. Fami, A. Rezvanfar, A. Asadi and S. Yazdani, 2008. Perceptions of paddy farmers towards sustainable agricultural technologies: Case of haraz catchments area in Mazandaran province of Iran. Am. J. Applied Sci., 5: 1384-1391. DOI: 10.3844/ajassp.2008.1384.1391

Buntod, P.C., P. Suksringam and A. Singseevo, 2010. Effects of learning environmental education on science process skills and critical thinking of mathayomsuksa 3 students with different learning achievements. J. Soc. Sci., 6: 60-63. DOI: 10.3844/jssp.2010.60.63
Fogg, B.J., 2002. Persuasive Technology: Using Computers to Change What We Think and Do. 1st Edn., Morgann Kaufmann Publishers, USA., ISBN-13: 9781558606432, pp: 312.

Goodland, R., 1995. The concept of environmental sustainability. Annual Rev. Ecol. Syst., 26: 1-24. DOI: 10.1146/annurev.es.26.110195.000245

Ismail, M.R., 2006. Pertanian Lestari. 1st Edn., Dewan Bahasa dan Pustaka, Malaysia, ISBN: 9836285431, pp: 229.

Kajikawa, Y., J. Ohno, Y. Takeda, K. Matsushima and H. Komiyama, 2007. Creating an academic landscape of sustainability science: An analysis of the citation network. Sustainabil. Sci., 2: 221-231. DOI: $10.1007 / \mathrm{s} 11625-007-0027-8$

Kalawsky, R.S., 2001. Human Factors Aspects of Virtual Design Environments in Education. JTAP Project 305. http://www.jisc.ac.uk/whatwedo/programmes/jtap/ humanfactors.aspx

Kuo, C., M. Tsai, C. Lai, Y. Shiau and C. Yeh et al., 2007. A New E-Platform Launched to Propagate Knowledge of Three Roles of Paddies. The Pennsylvania State University. http://citeseerx.ist.psu.edu/viewdoc/summary?doi= 10.1.1.102.6260

Kuo, C., Y. Shiau, C. Huang, C. Shen and W. Tsai, 2004. Application of virtual reality in ecological farmland navigating system. Proceeding of the 7th International Conference on High Performance Computing and Grid in Asia Pacific Region, July 20-22, National Center for High Performance Comput., Hsinchu, Taiwan, pp: 285-288. DOI: 10.1109/HPCASIA.2004.1324047

Murad, M.W., N.H.N. Mustapha and C. Siwar, 2008. Review of Malaysian agricultural policies with regards to sustainability. Am. J. Environ. Sci., 4: 608-614. DOI: 10.3844/ajessp.2008.608.614

Mustapha, N.H. and M.F.M. Jani, 1995. Pembangunan Pertanian Lestari. 1st Edn., Penerbit University Kebangsaan Malaysia, Malaysia, ISBN: 9679423301, pp: 389.

Othman, Z., A. Muhammad and M.A.A. Bakar, 2010. A sustainable paddy farming practice in West Malaysia. Int. J. Interdisciplinary Soc. Sci., 5: 425-438.

Pereira, A.G., 2006. Moving Worldviews: Reshaping Sciences, Policies and Practices for Endogenous Sustainable Development. 1st Edn., ETC/Compas, Leusden, ISBN-10: 9077347097, pp: 4342. 
Salam, S.N.A., W.A.J.W. Yahaya and A.M. Ali, 2010. Using persuasive design principles in motivational feeling towards Children Dental Anxiety (CDA). Persuasive Technol., 6137: 223-237. DOI: 10.1007/978-3-642-13226-1_23
Sharghi, T., H. Sedighi and A.R. Eftekhari, 2010. Effective factors in achieving sustainable agriculture. Am. J. Agric. Biol. Sci., 5: 235-241. DOI: 10.3844/ajabssp.2010.235.241 